\title{
Microspatial analysis of arsenic distribution in California mine wastes to better inform arsenic bioaccessibility
}

\author{
ABBIGAEL V ELI AND CHRISTOPHER S KIM
}

Chapman University

Presenting Author: aeli@chapman.edu

As a result of the extraction and processing of ore from gold and silver mines such as those found throughout the state of California, USA, elevated concentrations of associated toxic metal(loid)s including arsenic (As) are often mobilized by the transport of mine wastes into surrounding communities. Finegrained particles can be dissolved through exposure to surface and rain water, become airborne and inhaled, or become attached to surfaces such as skin and food and ingested, making their bioaccessibility extremely relevant. It is important, then, to understand how As bioaccessibility is affected by the spatial distribution of As within fine-grained particles, as a correlation between As distribution within a particle and As bioaccessibility could inform risk assessment and remediation efforts.

Bulk mine waste samples were collected from the Red Hill Mercury Mine in Tustin, CA and the Empire Gold Mine in Grass Valley, CA and separated by particle size through a dry-sieving method to generate eleven size fractions. BET surface area analysis was conducted on each fraction (ranging from $>2830 \mu \mathrm{m}$ to $<20 \mu \mathrm{m}$ ). Arsenic distribution and speciation were mapped by micro-X-ray fluorescence $(\mu \mathrm{XRF})$ and extended X-ray absorption fine structure (EXAFS) spectroscopy at beam lines 10-2, 4-2, and 11-2 at the Stanford Synchrotron Radiation Lightsource. Open-source software programs QuPath (0.2.1) and QGIS (3.10.7) were used to identify particles in $\mu$ XRF maps and quantify their areas, As concentrations, and spatial distribution at the microscale.

Our previous studies have demonstrated correlations between particle size, surface area, and As bioaccessibility, with smaller particles exhibiting increased surface area and higher As bioaccessibility. The ongoing spatial analysis work of this group complements these previous results by showing a correlation between surface versus interior As enrichment/depletion and As bioaccessibility. Based on previous results, we expect to see a positive correlation between As bioaccessibility and particles with surface As enrichment/interior As depletion. Conversely, we expect to see a negative correlation between As bioaccessibility and particles with surface As depletion/interior As enrichment. Moving forward, the spatial analysis process could be applied to a broad range of particle size fractions to determine a possible relationship between size fraction and As distribution within particles. 